\title{
Classification of circulation types over Eastern Mediterranean using a Self Organizing Map approach
}

$3 \times 4$ SOM of $500 \mathrm{hPa}$ geopotential height winter anomalies for 1971-2000
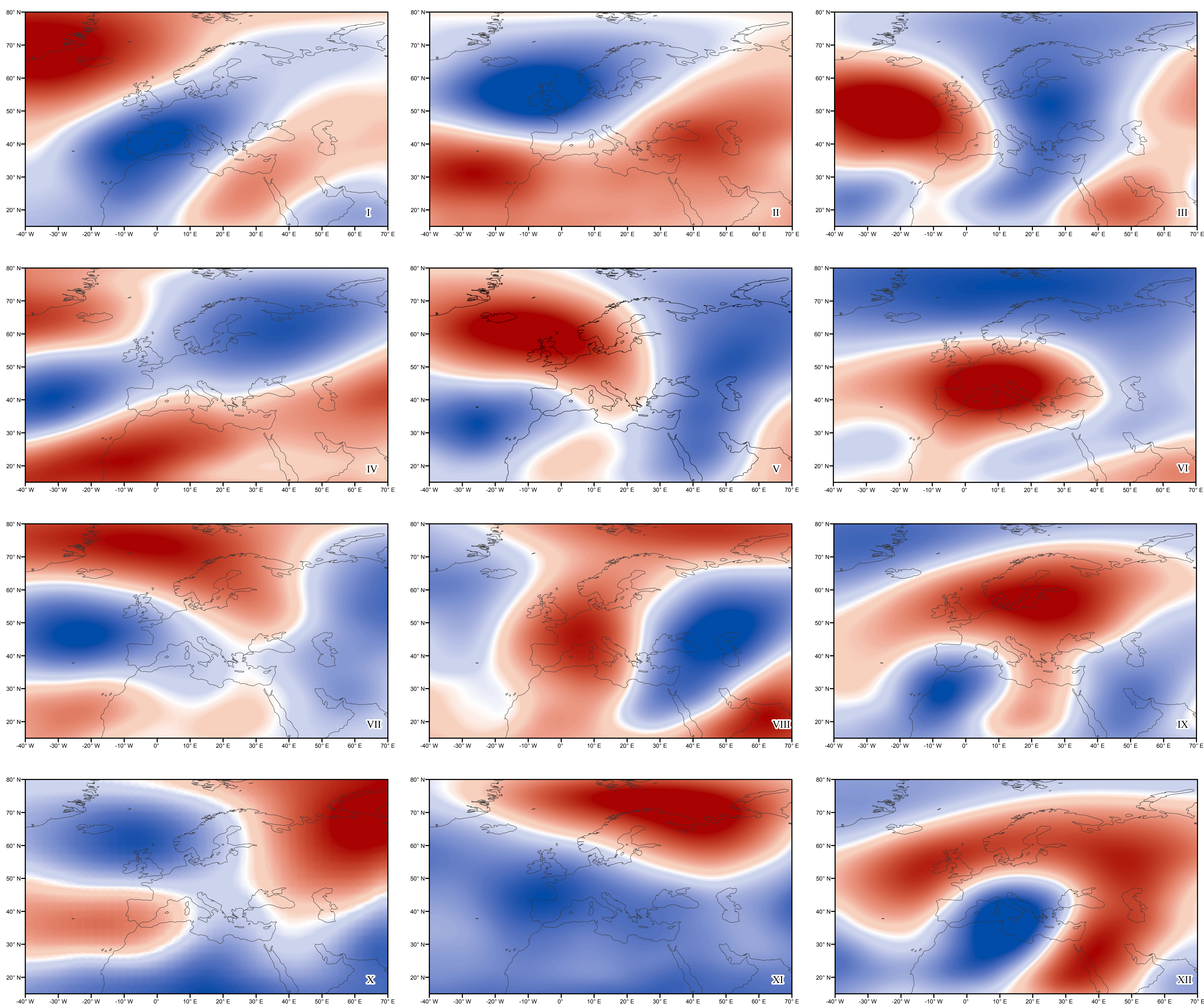
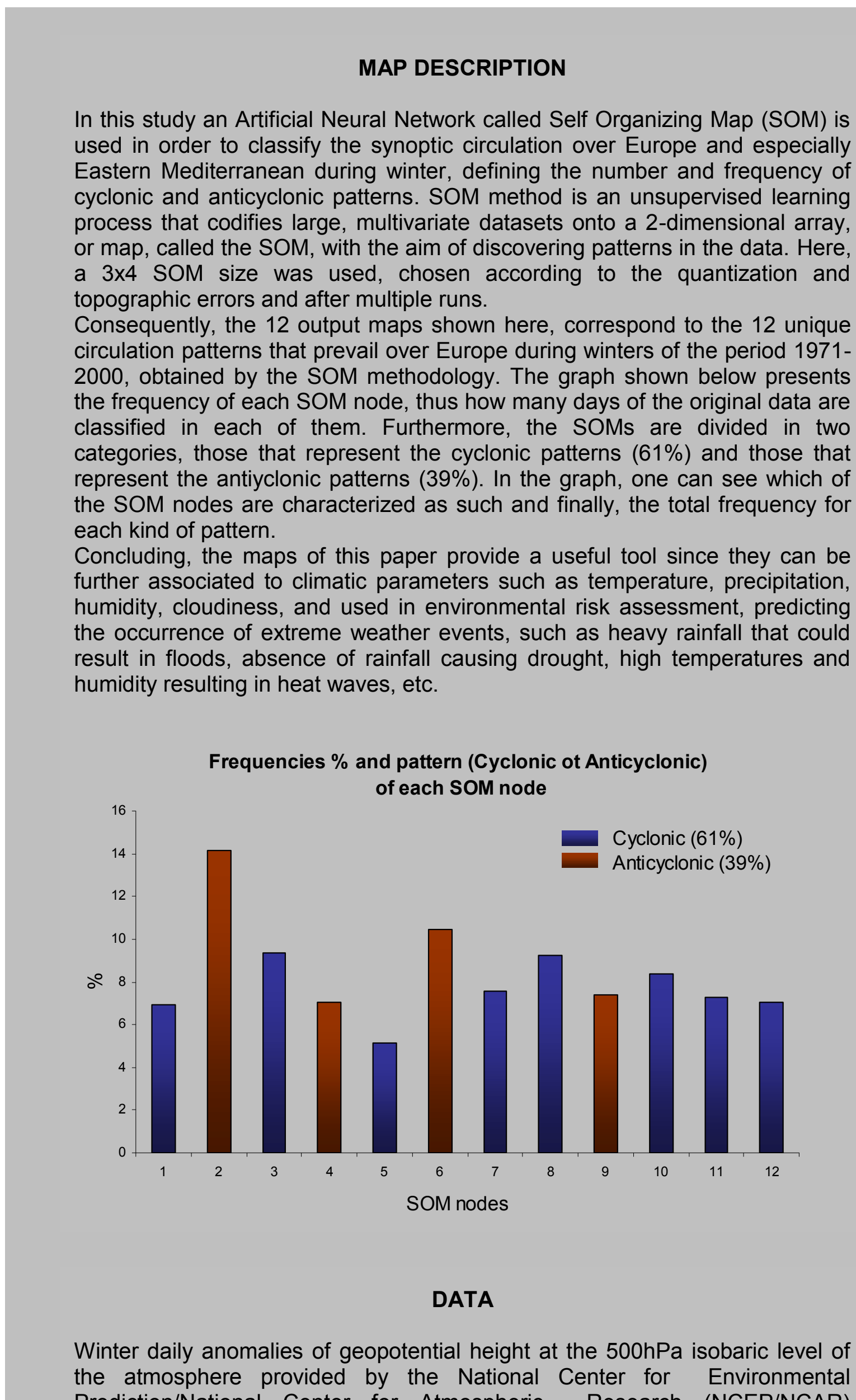

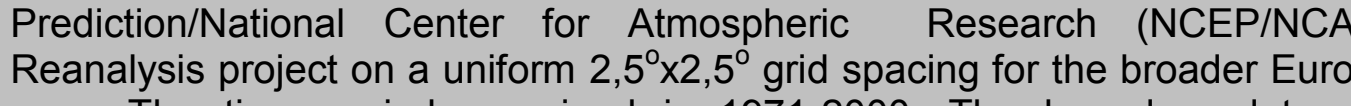

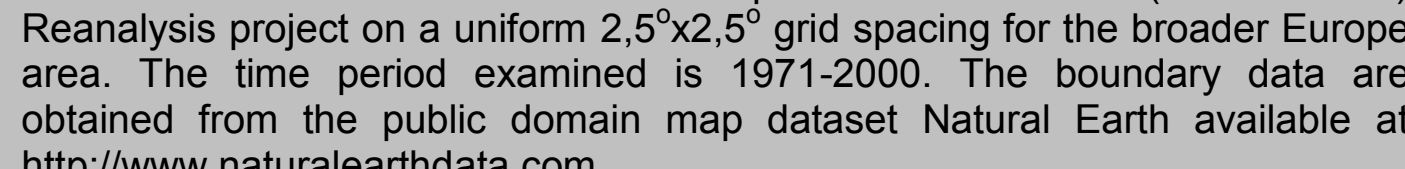

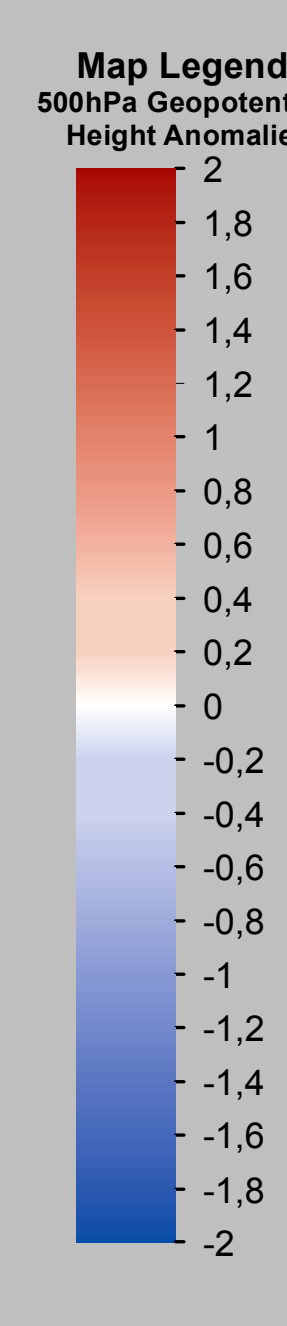

$-1.000$ COORDINATE SYSTEM
Geographic Coordinate System: GCS WGS 1984 Scale: $1: 70.000 .000$
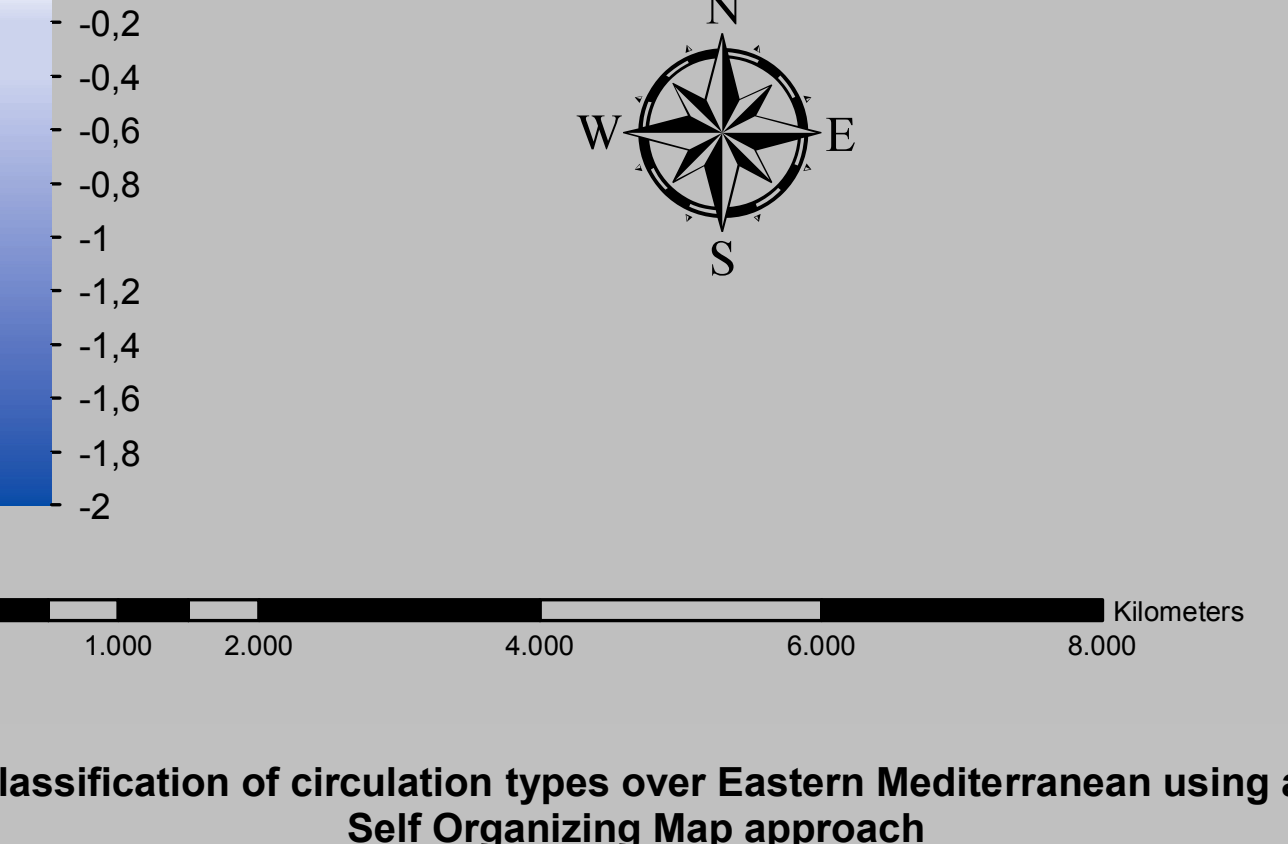

OE. Rousi", A. Mimis', M. Stamou', C,

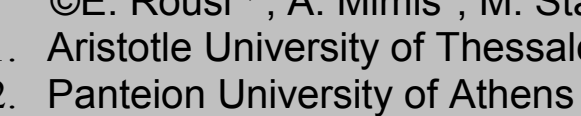
Pantion University of Athens
Corresponding Author: erousi@geo.auth. 